\title{
Assessment of habitat fragmentation caused by traffic networks and identifying key affected areas to facilitate rare wildlife conservation in China
}

\author{
Lu Zhang ${ }^{\mathrm{A}}$, Tian Dong ${ }^{\mathrm{A}}$, Weihua $^{\mathrm{X}} \mathrm{u}^{\mathrm{A}, \mathrm{B}}$ and Zhiyun Ouyang ${ }^{\mathrm{A}}$

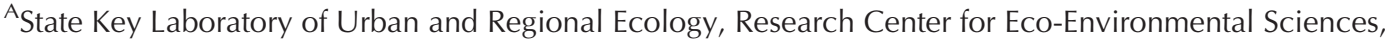 \\ Chinese Academy of Sciences, Beijing 100085, China. \\ ${ }^{\mathrm{B}}$ Corresponding author. Email: xuweihua@rcees.ac.cn
}

\begin{abstract}
Context. Traffic network construction is an essential method for enhancing the effectiveness of economic activities, but it can have various negative impacts on rare wildlife. In China, the rate of road construction has increased by over $300 \%$ during the past decade; however, the resulting fragmentation of rare habitats at a national scale remains uncertain.

Aims. This study mainly aimed to evaluate the impacts of road and railway networks on the fragmentation of habitats of endangered species in China. Another aim is to identify the key areas and road sections where improvements to habitat connectivity and integrity are urgently required.

Methods. We documented habitat information for 21 indicator species on the basis of two comprehensive datasets and over 120 previous studies. We combined this information to simulate the habitats of all these species by integrating a conceptual model and expert knowledge. We calculated the rates of change on the basis of three geometric habitat patterns for each species in traffic-clearing scenarios and road- and railway-overlay scenarios. An optimal algorithm, the core-area zonation cell-removal rule, was used to identify rare habitats affected by severe traffic stress.

Key results. According to our analysis, we ranked the road density in the habitats of all species as a straightforward evaluation of transportation stress. Among the different species considered, snow leopard (Panthera uncia), Cabot's tragopan (Tragopan caboti) and Przewalski's gazelle (Procapra przewalskii) appeared to be affected most severely by road-induced fragmentation. In addition, we classified five patterns of habitat fragmentation among species to facilitate wildlife management. On the basis of the trade-off between road density and conservation value per unit, we identified 17 unit sets as key traffic-affected areas, including 40 highways, 62 national roads and 51 railway sections.

Conclusions. Our results suggested that assessing the distributions of several key species can be effective in evaluating the impacts of roads on rare-wildlife habitats in China. Our results also indicated that the habitats of narrowly distributed species, such as Chinese alligator and Sichuan partridge, have high traffic densities, but core habitat degradation is even more serious for the habitats of species with higher intrinsic mobility or greater area requirements. Finally, we suggest that future conservation programs and restoration efforts should concentrate on roads or railway sections in the key areas that we identified.

Implications. In the present study, we obtained spatially explicit findings related to the maintenance of rare wildlife in a region where wildlife-protection information is lacking. Our site-selection results can be used to allocate highly limited conservation resources in a more efficient and effective manner, to facilitate wildlife protection in this region.
\end{abstract}

Received 24 June 2014, accepted 24 May 2015, published online 15 July 2015

\section{Introduction}

Roads and other types of infrastructure that require clearing are known to have widespread negative environmental impacts on natural habitats and ecosystems worldwide (Coffin 2007; Laurance et al. 2009). Thus, traffic has deleterious effects on natural ecosystems and their wildlife composition. As a key component and indicator of human effects (Scholes and Biggs 2004; Huettmann 2012), assessing how roads may affect natural habitats on a landscape scale is important for rapid assessments of the quality of rare habitats and for selecting conservation strategies, especially in developing regions (Li et al. 2009). In
2002, the construction of a harmonious society was proposed by the Chinese government as a state policy. One of the main characteristics of this policy is the maintenance of harmony between humans and nature. However, between 2000 and 2010, the traffic network increased by over 2.3 million $\mathrm{km}$ in China, with highways increasing by $354 \%$ and railways by $33.8 \%$ (National Bureau of Statistics of the People's Republic of China 2003, 2006, 2011). This extremely high rate of road construction has increased the accessibility of remote areas, facilitated mining and the development of hydro-electric power and recreation, as well as related human activities, such as the retail and tourism 
sectors. However, the rate of road expansion is so great that it often overwhelms the capacity of environmental managers (Laurance et al. 2014). If uncontrolled, this trend will accelerate habitat fragmentation, reduce forest or grass regrowth, and, thus, threaten the survival of rare wildlife (Forman and Alexander 1998). Consequently, two problems have been highlighted, namely, the impact of traffic construction on rare habitats and the regions that are affected most by severe landscape fragmentation, which is associated with roads and railways, and, thus, the need to take urgent measures to relieve the conflict between wildlife protection and traffic projects.

Roads and railways have various direct and indirect impacts on wildlife, and several methods have been proposed to identify and quantify traffic networks that have a negative impact on wildlife, such as road mortality, habitat loss and reduction in habitat quality (Forman et al. 2003; Linke et al. 2005). Vehicleinduced mortality has the most direct influence on the wildlife population and it can decrease the size of local populations of the most common species (Van Langevelde et al. 2009). However, for many endangered or rare species, the impact is most likely to lead to local extinction (Grilo et al. 2009). An individual can avoid being killed on roads, but their behavioural patterns tend to be modified in response to traffic noise (López et al. 2010; Byrnes et al. 2012). The flushing out and movement of rare species as a result of new road networks can have a detrimental effect on the breeding success or physiological health of these species (Morgan et al. 2012). In addition to the visible influences that are generally limited to the road itself or adjacent road verges, roads may act as filters or barriers to wildlife movement within their habitat, thereby affecting gene flow (Blair et al. 2012) and population migration (Taylor and Goldingay 2010). Furthermore, if exotic species or infectious diseases invade parts of their habitat, the indigenous species are confined by these physical barriers, which may increase the risk of local extinction.

On a broader landscape scale, the ubiquitous roadderived 'barrier effect' causes habitat fragmentation, which has a profound negative impact on the sustainability of species (Rondinini and Doncaster 2002; Jackson and Fahrig 2011). Increasing habitat fragmentation is frequently associated with complex permanent effects on wild organisms. This phenomenon generally decreases the accessibility to resources for a wildlife population or even restricts the population within an isolated and more vulnerable habitat patch. As a result, the genetic diversity, growth rate and size of the population are affected detrimentally. Therefore, the degree of habitat fragmentation is often regarded as a proxy for determining the pressure on wildlife survival caused by transport infrastructures. The measurement of fragmentation (Lu et al. 2012) or habitat connectivity (Kindlmann and Burel 2008) usually relies on indices of landscape configurations, either static or dynamic, based on land use and ecosystem mapping rather than behavioural monitoring data, which are unavailable on a large scale. Many studies have reported several inherent limitations of landscape indices ( $\mathrm{Li}$ and $\mathrm{Wu}$ 2004; Tiefenbacher, 2012), but the obvious advantages of this method include evaluation of habitat quality, the identification of important regions disturbed by roads, and the formulation of predictive conservation decisions (Uuemaa et al. 2009). Thus, various types of software have been developed to facilitate the calculation of indices, particularly Fragstats (McGarigal et al. 2012), which includes over 70 landscape indices for measuring landscape patterns at patch, class and landscape levels.

Recently, the Chinese government and researchers recognised that major transport system-related fragmentation is a severe threat to the survival of rare and endangered species. Therefore, numerous field studies have been conducted with the following two main objectives: (1) to compare the differences in circadian activity, home range, population size, location, and movement patterns of rare species before and after road construction (Li et al. 2009, 2010; Fan et al. 2011), thereby determining whether the behavioural patterns of species are affected by traffic barriers; (2) to assess the changes in spatial patterns or other ecological features (e.g. ecological risk and connectivity) for each type of ecosystem as a result of road networks (Liu et al. 2008; Harris 2008). The result of these studies can facilitate comparisons between the impacts of roads and railways on different fauna with various ecological characteristics, as well as partly establishing the local biodiversity richness. However, the areas with rich biodiversity but severe traffic infrastructure impacts have not been characterised. This site-selection information would be valuable for facilitating further conservation planning and for allocating road-conservation resources.

Therefore, the present study aimed to address the following three specific objectives: (1) to evaluate the level of impact of transportation (roads and railways) on rare habitats for several conspicuous indicator species in China; (2) to identify the most severely affected areas to define a set of critical habitat units with maximum traffic network disturbance; and (3) to identify particular road and railway sections in key areas, thereby yielding useful information for innovative conservation planning, particularly for future road construction.

\section{Materials and methods}

\section{Data acquisition and collection}

The present study aimed to measure the impact of traffic on rare habitat fragmentation in a wide range of ground-dwelling species, but most of them are still being studied and their habitats are still not well known. Therefore, we selected several species with populations that are sensitive (species with lower reproductive rates, greater mobilities, and larger body sizes) to habitat fragmentation and that are well known indicator species in different geographical regions, where their habitats have been simulated as surrogates for rare habitats (Williams et al. 2000). Thus, the definition of a rare habitat employed in the present study was based on those of 21 indicator species.

All of these species were selected according to the following three criteria: (1) species listed as Critically Endangered (CR) or Endangered (EN) in the International Union for Conservation of Nature (IUCN) Red List (IUCN 2013), or Level I in the Law of the People's Republic of China on the Protection of Wildlife (State Forestry Administration of China 2010); (2) species that have been well studied for many years in the field by other researchers to simulate their habitats; and (3) the overlapping habitats included representative natural ecosystems for each of the eco-regions (ECRs; Olson et al. 2001) in China (Fig. 1). These biogeographic regions have been widely cited as analytical units for conservation assessment and planning, where they approximate the ecosystem types and distributions of species 


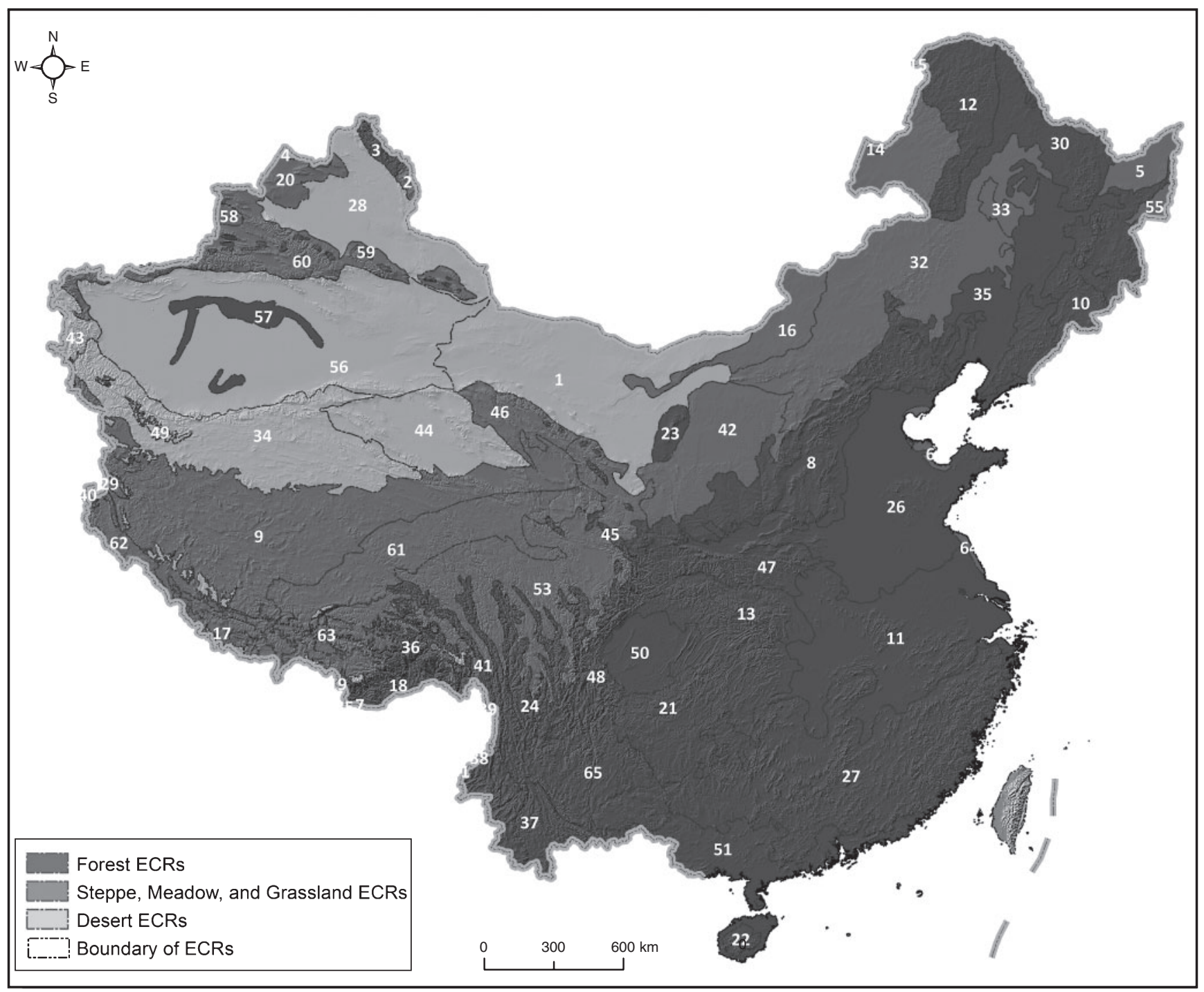

Fig. 1. Spatial pattern of eco-regions (ECRs) in China. 1, Alashan Plateau semi-desert; 2, Altai alpine meadow and tundra; 3, Altai montane forest and forest steppe; 4, Altai steppe and semi-desert; 5, Amur meadow steppe; 6, Bohai Sea saline meadow; 7, Brahmaputra Valley semi-evergreen forests; 8, Central China loess plateau mixed forests; 9, Central Tibetan Plateau alpine steppe; 10, Changbai Mountains mixed forests; 11, Changjiang Plain evergreen forests; 12, Da Hinggan-Dzhagdy Mountains conifer forests; 13, Daba Mountains evergreen forests; 14, Daurian forest steppe; 15, East Siberian taiga; 16, Eastern Gobi desert steppe; 17, Eastern Himalayan alpine shrub and meadows; 18, Eastern Himalayan broadleaf forests; 19, Eastern Himalayan subalpine conifer forests; 20, Emin Valley steppe; 21, Guizhou Plateau broadleaf and mixed forests; 22, Hainan Island monsoon rain forests; 23, Helanshan montane conifer forests; 24, Hengduan Mountains subalpine conifer forests; 25, Himalayan subtropical broadleaf forests; 26, Huang He Plain mixed forests; 27, Jian Nan subtropical evergreen forests; 28, Junggar Basin semi-desert; 29, Karakoram-West Tibetan Plateau alpine steppe; 30, Manchurian mixed forests; 31, Mizoram-Manipur-Kachin rain forests; 32 , Mongolian-Manchurian grassland; 33, Nenjiang River grassland; 34, North Tibetan Plateau-Kunlun Mountains alpine desert; 35, Northeast China Plain deciduous forests; 36, Northeastern Himalayan subalpine conifer forests; 37, Northern Indochina subtropical forests; 38, Northern Triangle subtropical forests; 39, Northern Triangle temperate forests; 40, Northwestern Himalayan alpine shrub and meadows; 41, Nujiang Langcang Gorge alpine conifer and mixed forests; 42, Ordos Plateau steppe; 43, Pamir alpine desert and tundra; 44, Qaidam Basin semi-desert; 45, Qilian Mountains conifer forests; 46, Qilian Mountains subalpine meadows; 47, Qin Ling Mountains deciduous forests; 48, Qionglai-Minshan conifer forests; 49, Rock and Ice; 50, Sichuan Basin evergreen broadleaf forests; 51, South China-Vietnam subtropical evergreen forests; 52, South China Sea Islands; 53, Southeast Tibet shrublands and meadows; 54, Southern Annamites montane rain forests; 55, Suiphun-Khanka meadows and forest meadows; 56, Taklimakan desert; 57, Tarim Basin deciduous forests and steppe; 58, Tian Shan foothill arid steppe; 59, Tian Shan montane conifer forests; 60, Tian Shan montane steppe and meadows; 61, Tibetan Plateau alpine shrublands and meadows; 62, Western Himalayan alpine shrub and Meadows; 63, Yarlung Tsangpo arid steppe; 64, Yellow Sea saline meadow; 65, Yunnan Plateau subtropical evergreen forests.

within which ecological processes interact most strongly, (Jenkins and Joppa 2009; Wu et al. 2011). For example, the habitat of chiru (Pantholops hodgsonii) covers the most of the typical ecosystem (e.g. alpine meadow and alpine steppe) found in the Tibetan plateau and it includes abundant rare species with similar distribution areas in this region.

By integrating these criteria and based on the advice of a decision-making body, i.e. the Ministry of Transport of the 
Table 1. Indicator species and their conservation levels CR, critically endangered; EN, endangered; VU, vulnerable; NT, near threatened; LC, least concern. TSN, taxonomic serial numbers, available at http://www.itis.gov

\begin{tabular}{|c|c|c|c|c|c|}
\hline ID & Name & Latin name & TSN & Class & IUCN level \\
\hline 1 & Snow leopard & Panther auncia & 183811 & Mammalia & EN \\
\hline 2 & Indian python & Python molurus & 202187 & Reptilia & NT \\
\hline 3 & Takin & Budorcas taxicolor & 625135 & Mammalia & VU \\
\hline 4 & Golden snub-nosed monkey & Rhinopithecus roxellana & 944261 & Mammalia & EN \\
\hline 5 & Sika deer & Cervus nippon & 180696 & Mammalia & $\mathrm{LC}$ \\
\hline 6 & Pygmy slow loris & Nycticebus pygmaeus & 572891 & Mammalia & VU \\
\hline 7 & Siberian Siberian tiger & Panthera tigris altaica & 726472 & Mammalia & EN \\
\hline 8 & Asian elephant & Elephas maximus & 584938 & Mammalia & EN \\
\hline 9 & Przewalski's gazelle & Procapra przewalskii & 625116 & Mammalia & EN \\
\hline 10 & Sichuan partridge & Arborophila rufipectus & 176038 & Aves & EN \\
\hline 11 & Chinese alligator & Alligator sinensis & 202209 & Reptilia & $\mathrm{CR}$ \\
\hline 12 & Black snub-nosed monkey & Rhinopithecus bieti & 944259 & Mammalia & EN \\
\hline 13 & Cabot's tragopan & Tragopan caboti & 176062 & Aves & VU \\
\hline 14 & Francois's leaf monkey & Trachypithecus francoisi & 573062 & Mammalia & EN \\
\hline 15 & Brown-eared pheasant & Crossoptilon mantchuricum & 176073 & Aves & VU \\
\hline 16 & Giant panda & Ailuropoda melanoleuca & 621845 & Mammalia & EN \\
\hline 17 & Sable & Martes zibellina & 621945 & Mammalia & $\mathrm{LC}$ \\
\hline 18 & Chiru & Pantholops hodgsonii & 625113 & Mammalia & EN \\
\hline 19 & Grey snub-nosed monkey & Rhinopithecus brelichi & 944260 & Mammalia & EN \\
\hline 20 & Black crested gibbon & Hylobates concolor & 573070 & Mammalia & $\mathrm{CR}$ \\
\hline 21 & Bactrian camel & Camelus ferus & 898263 & Mammalia & $\mathrm{CR}$ \\
\hline
\end{tabular}

People's Republic of China, 21 indicator species were selected, as shown in Table 1. Our species-selection process was based on several ecological and social assumptions. First, endangered species attract public attention and thus they must be prioritised. Second, species with direct economic value should also be given higher-priority protection, which is why we added sika deer, Asian elephant, sable, and Siberian tiger to the final list. Third, species with important cultural value should be protected as a priority, such as the giant panda, chiru, Chinese alligator, and three snub-nosed monkey species. These species have long been regarded as national treasures in China, thereby inspiring empirical researchers to map their habitats. Fourth, umbrella species should be given priority for protection. The distributions of umbrella species cover a wide range and they encompass the habitats of many other species (Primack 2012). Thus, by protecting these species, many other species can be protected simultaneously. For example, the habitat of the Indian python covers almost the entire tropical rain forest in China, which includes the habitats of rare species with similar ecological niches. Finally, some rare migratory birds such as the red-crowned crane (Grus japonensis) and black-necked crane (Grus nigricollis) were excluded from the list because they have behaviours (e.g. habitat use and migration patterns) different from those of non-migratory species.

To obtain up-to-date information on the distribution of these indicator species, we used a large number of datasets to produce habitat simulations, including the China Species Information System (WCSC 2001) and the Chinese Biodiversity Information System (CAS 2005). Using these datasets, we collected the major vegetation types, altitude and other habitat information (e.g. aspect and slope) for each species. All of the datasets included complete information, but there were generally minor discrepancies. Therefore, a combined set was generated to ensure the accuracy of our final dataset. Finally, we reviewed all of the available studies of each species in the list that contained either spatially explicit habitat maps or local extinction information.

A map of ecosystem types was obtained from the $1: 1000000$ scale vegetation atlas of China, which was digitised by the Institute of Botany, Chinese Academy of Sciences. Elevation data were generated from a mosaic of Shuttle Radar Topography Mission data. Administrative boundaries and water-system data were provided by the National Fundamental Geographical Information Centre in 2009. The road data were digitised in vector format by the Ministry of Transport of the People's Republic of China in 2010. The railway data were obtained from the Ministry of Railways of the People's Republic of China in 2010. Data from the entire land surface of China were included, but data from Taiwan, Hongkong, Macao and small islands were not included due to lack of availability.

\section{Mapping of indicator species as rare-habitat indictor}

The habitat-mapping process referenced a simplified resourcebased habitat model produced by Nielsen et al. (2010), which is very similar to a previously described conceptual model (Liu et al. 2001; Xu et al. 2009). In this model, the definition of a potential habitat (suitable ecological niche) is the product of weighted factors of ecological niche items (Eqn 1), as follows:

$$
p H Q_{i j}=R_{i} \sum_{m=1}^{n} I_{m} W_{m},
$$

where the potential habitat quality $(p H Q)$ for Pixel $i$ of Ecosystem $j$ is estimated as the sum of the product between the area of ecological Niche $I$ for Factors $m$ and $W$, a weight that indicates the significance of different factors for species habitat selection. $R_{\mathrm{i}}=0$ or 1 represents the coarse distributional regions of the 
indicator species. $R_{\mathrm{i}}=0$ means that there are no historical distributions of indicator species in Pixel $i$.

We simplified the model further according to our aims and the data available. In this study, the aim of habitat prediction was to identify potential habitats for each indicator species in the form of a binary map, so all of the variables were denoted as 0 or 1 to indicate the absence or presence of indicator species, and the weight of each factor could be ignored (Eqn 2), as follows:

$$
p H_{i}=C_{i} I E,
$$

where $p H_{i}$ indicates whether Polygon $i$ is a potential habitat; $E$ is a suitable ecosystem for the species; $I$ represents the overlap of suitable elevation, slope, and aspect factors for the species; and $C_{i}$ is the record of historical distributions of indicator species in County $i$. For each indicator species, a Boolean habitat image was generated where 1 denoted an 'available habitat patch', including the actual habitat and the modelled potential habitat, whereas 0 denoted an 'unavailable habitat patch'.

For each species, we recorded the distribution in counties, altitude, ecosystems, protected areas and geographic ranges (mountain, valley) on two web databases. These data were collected by 15 institutes of the Chinese Academy of Sciences in the past 45 years, including a mixture of historical and recent data obtained in the field. Previous studies were downloaded from China National Knowledge Infrastructure (http://www.cnki.net/, verified 31 May 2013). These reports had to include maps or descriptions of the explicit range of species. Species habitat mapping comprised three steps. The first step generated the coarsest habitat map, where we added 21 fields ( 21 species) to the attribute table of a county shpfile data and then, for each field, we assigned 1 to a county where the species appeared and 0 otherwise. These data were converted into 21 ESRI GRID datasets with a resolution of $90 \mathrm{~m}$. The ecosystem variable was generated using the same method as for the county variable. A suitable elevation for each species was transformed into 1, using the reclassify tool in Arcgis10.0, with 0 for an unsuitable elevation. Next, these three variables were multiplied. On the basis of the coarsest habitat map, we then removed absence patches for every species in each county according to the protected areas and geographic-range information. For example, Species A was distributed in County B, but only in Protected area $\mathrm{C}$ in County B. Therefore, we removed all of the suitable patches except the Protected area $\mathrm{C}$ within County B. So as to improve the accuracy of the habitat maps, we removed abandoned patches for every species that had been demonstrated clearly in previous studies. For example, Mountain A was a historical habitat of Species B, but 10 years of field research demonstrated that Species B had disappeared from Mountain A; thus, we deleted the habitat patches from A.

\section{Fragmentation analysis and key-area identification}

The development of transport infrastructure alters the structure of the habitat landscape and, thus, the behavioural patterns of rare species found in the habitat (Hinam and St Clair 2008; Reiter et al. 2013). Transport networks produce a large number of edges and a smaller number of core habitats, which are known as biological edge effects. Simultaneously, the number of habitat patches increases and the patch size decreases as a result of road and railway construction, which reduces population sizes and the probability of wildlife persistence. Many indices have been developed to measure this fragmentation, although most are strongly related. Therefore, only three indices with different ecological meanings were employed in our analysis (Eqns 3-5; Jaeger 2000; Moser et al. 2007), and they were as follows:

Effective mesh size (EMS),

$$
E M S=\frac{1}{A_{\text {total }}} \sum_{i=1}^{n} A_{i} A_{i}^{c m p l},
$$

where $A_{\text {total }}$ is the total area of the habitat and $A_{i}$ is the area of Patch $i . A_{i}^{c m p l}$ is the area of the complete patch of which $A_{i}$ is part of the area on the other side of the boundaries of the habitat (Fig. 2). A decrease in EMS indicates that the proportions of the large and integrated habitat patches are reduced.

Edge density (ED),

$$
E D=\frac{E}{A_{t}},
$$

where $E$ is the total edge length ( $\mathrm{m}$ ) distributed in the landscape. A high ED value indicates that a relatively high barrier effect exists in the landscape.

Area-weighted mean shape index (AWMSI),

$$
A W M S I=\frac{\sum_{i=1}^{m} p_{i} A_{i} / 2 \sqrt{\pi \times A_{i}}}{A_{t}},
$$

where $P_{i}$ is the perimeter (m) of Patch $i$. A decrease in AWMSI means that the shape of the habitat patch has become more complex. This index is known to be suitable for measuring linear elements that cause fragmentation, such as roads or railways.

In the first step, all of the metrics were calculated without any roads or railways to measure the characteristics of the pre-fragmented landscape (traffic-clearing scenario). Next, to estimate the contributions of habitat-fragmentation effects when producing a linear infrastructure, we calculated the indices with road and railway intersections (road- and railwayoverlay scenario). In each step, we also calculated the rate of change for the indices for all indicator species. Patches smaller than $1 \mathrm{~km}^{2}$ were removed owing to errors in image processing and, although some were accurate, none of the indicator species tended to use such very small patches. All of the indices were calculated using Arcgis10.0 with ESRIGRID data. Finally, the overall road and railway densities were counted with 50196 units of $10 \times 10 \mathrm{~km}$ square for all of the indicator species to determine the transport pressure. High road- and railway-density units with a high richness of indicator species were identified using the modified core-area zonation cell-removal rule (Moilanen 2007), as described by Eqn 6, as follows:

$$
\delta_{i}=\max _{j} D_{i j}(S) \omega_{i} / H_{i},
$$

where $D_{i j}(S)$ is the proportion of the remaining length of Road class $j$ among the total length distributed in the remaining set of units, $S$, when Unit $i$ is removed; $\omega_{i}$ is the weight (or priority) of Road class $j$, which is determined by the analytic hierarchy process method to explain the effects of different road or railway classes on habitat fragmentation; and $H_{i}$ is the habitat importance value defined by Eqn 7, as follows: 


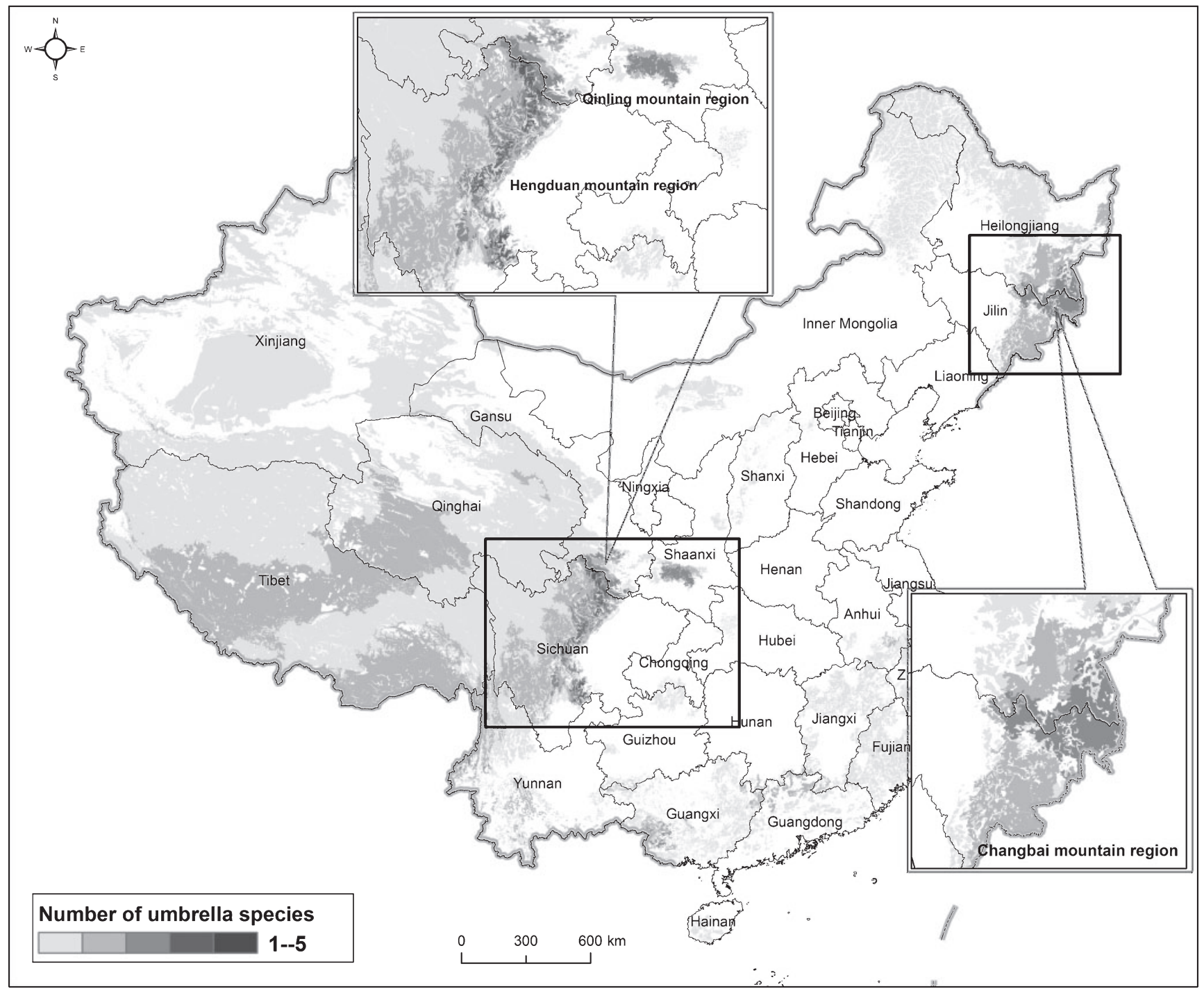

Fig. 2. Distribution of indicator species.

$$
H_{i}=1 /\left(n_{i}+1\right),
$$

where $n_{i}$ is the number of indicator species present in Unit $i$.

Equation 6 means that when parts of the roads are removed, the proportion located in each remaining unit increases. This equation aims to retain a priority rank for all units according to the value of $\delta_{i}$. Units with a high $\delta_{i}$ value denote areas with a high protection value, but they are affected by severe traffic impacts. We treated these units as key areas and road sections within these areas were identified in detail to facilitate conservation decision making.

\section{Results}

\section{Distribution of transport networks and indicator species}

On the basis of previous research, we simulated the spatial distributions of the indicator species and the overlay results are shown in Fig. 2.

According to Fig. 2, the Hengduan Mountain region located in the junction area between the South Asia tropic zone and
Qinghai-Tibet Plateau supports habitats for five indicator species, whereas the Changbai Mountain region in northeastern China supports three indicator species. The overall distribution pattern of the indicator species is similar to the priority biodiversity-protection areas in China, and it also contains most of the typical vegetation types in each ECR. In total, $90.7 \%$ of the important nature reserves for terrestrial wildlife conservation are included in the rare habitats. The main gaps are two Pere David's deer (Elaphurus davidianus) reserves located in Hubei and Jiangsu provinces. This species was not selected because the $\sim 2000$ remaining individuals are a domesticated population and they are listed as Extinct in the wild in the IUCN Red List (IUCN 2013).

\section{Habitat fragmentation caused by the transport network}

Among species, we found that the habitat of the Chinese alligator, a rare wetland species, had the maximum road density, whereas the road densities for the Tibetan antelope and Cabot's tragopan 


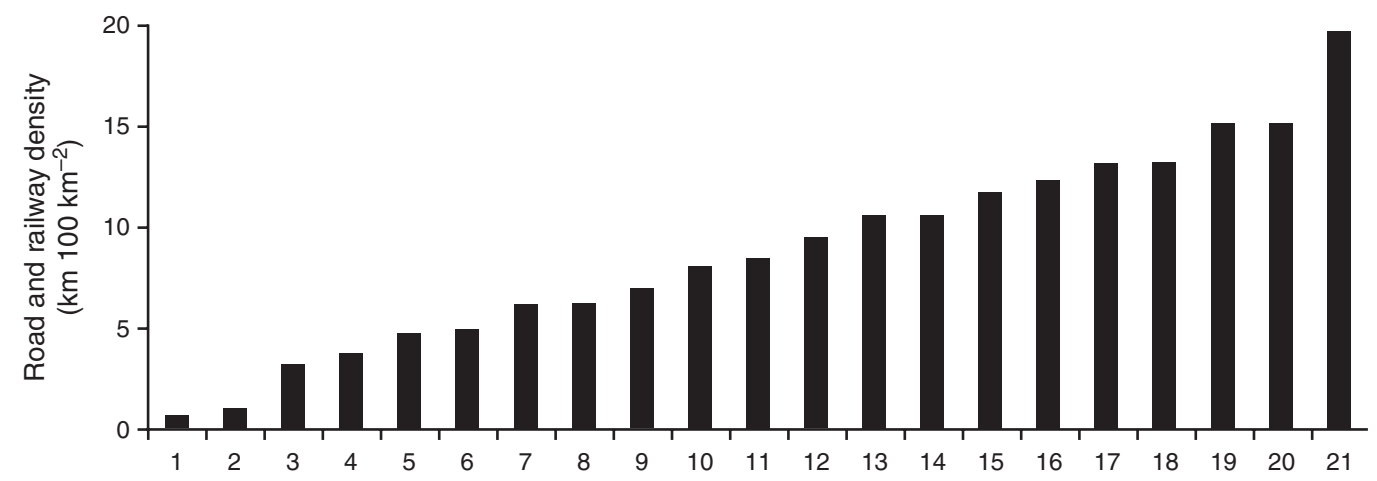

Fig. 3. Road and railway density of indicator species $\left(\mathrm{km}\right.$ per $\left.100 \mathrm{~km}^{2}\right)$. 1, Bactrian camel; 2, Chiru; 3, snow leopard; 4, Takin; 5, golden snub-nosed monkey; 6, sable; 7, black snub-nosed monkey; 8, giant panda; 9, Asian elephant; 10, Siberian tiger; 11, grey snub-nosed monkey; 12, black crested gibbon; 13, Francois' leaf monkey; 14, brown-eared pheasant; 15, Indian python; 16, Sika deer; 17, Cabot's tragopan; 18, Przewalski's gazelle; 19, Sichuan partridge; 20, pygmy slow loris; 21, Chinese alligator.

were significantly lower than for the others (Fig. 3). The statistical analysis based on the three landscape indices and the changes in their proportions demonstrated the contributions of habitat fragmentation caused by roads and railways throughout China. Given the cumulative effect of the three metrics owing to road and railway construction, we found that the snow leopard had been affected most severely among the 21 indicator species, whereas the Sichuan partridge had been affected the least (Fig. 4).

Using K-means clustering in SPSS19.0, the species were classified into five types on the basis of their different modes of habitat change. The first type comprised the snow leopard, Przewalski's gazelle and Bactrian camel, which are distributed in a wide range of deserts in western China, and the golden snubnosed monkey, giant panda, black snub-nosed monkey and takin, which are distributed in the Hengduan Mountains of southwestern China. This group of indicator species had high EMS and AWMSI values but low ED values. Thus, although the road density was not high in these habitats, their locations tended to cross the core habitat and the uniformity of patch shape in these habitats was apparently decreasing. The second type comprised the Indian python and sable, and the third type comprised sika deer, Siberian tiger, black crested gibbon and Sichuan partridge, which had patterns of change similar to those of the first type, although the second type clearly had higher EMS values and lower ED values than did all the other types, and the third type had fairly high ED values that could not be ignored. The ED values of the fourth type, which comprised Cabot's tragopan, brown-eared pheasant, Francois's leaf monkey and Chinese alligator, were higher than the AWMSI values, thereby indicating the presence of a barrier effect caused by a high edge density, which should be highlighted in conservation planning. The remaining three species comprised the last type, i.e. chiru, grey snub-nosed monkey and Asian elephant, which was marked by a change in the dominant landscape index from a decreasing rate for EMS to a decreasing rate for AWMSI.

\section{Identification of key habitats with severe transport-network disturbance}

Figure 5 shows the distribution of the $\delta_{i}$ values. Clearly, the rare habitat units with severe affects of traffic $\left(0.95>\delta_{i}>0.75\right)$ were mainly concentrated in the Changbai Mountains, east of the Nanling Mountains, Jinggang Mountains, Shiwan Great Mountains, Liangshan Mountains, Wuliang Mountains and Qinghai Lake area. The habitat units with extremely severe traffic impacts $\left(\delta_{i}>0.95\right)$ were usually distributed in the core areas within severely affected habitats $\left(0.95>\delta_{i}>0.75\right)$.

Based on the analysis of the extremely severely affected regions, we identified the major road and railway sections that affect rare habitats and their positions, i.e. 40 highway sections, 62 national road sections, and 51 railway sections, as shown in Table 2. For example, complex traffic networks, including highway sections G10, G11 and G12, national road sections G201, G301, G302 and G303 and railway sections Line Fuqian, Line Jiafu, Line Mujia, Line Lindong, Line Binsui, Line Mutu, Line Changtu, Line Helong, Line Yanbai, Line Hunbai, Line Meiji and Line Yada, located in the area north of Ji' an City and Mishan City in north-eastern China have severe negative impacts on the populations of Siberian tiger, sika deer and sable. The area around Qinghai Lake includes fewer road sections, but it should also be highlighted because it contains the last remaining habitat of Przewalski's gazelle.

\section{Discussion}

Considerations related to wildlife behaviour and habitat estimation

In the present study, we attempted to gain insights into wildlife protection in a region of the Earth where such information is severely lacking. First, we produced spatially explicit habitat maps of 21 endangered species with limited field data. The habitats of these flagship species covered all of the representative natural ecosystems in each of the ECRs and they encompassed $90.7 \%$ of the total area of national wildlife nature reserves. On the basis of these maps, we performed an intersect analysis between the habitats and traffic networks to measure the landscape-scale impacts of roads and railway. These results will be valuable for the future monitoring and protection of these species and their habitats.

However, the impact of habitat fragmentation is species specific. Most of the indicator species considered in the 


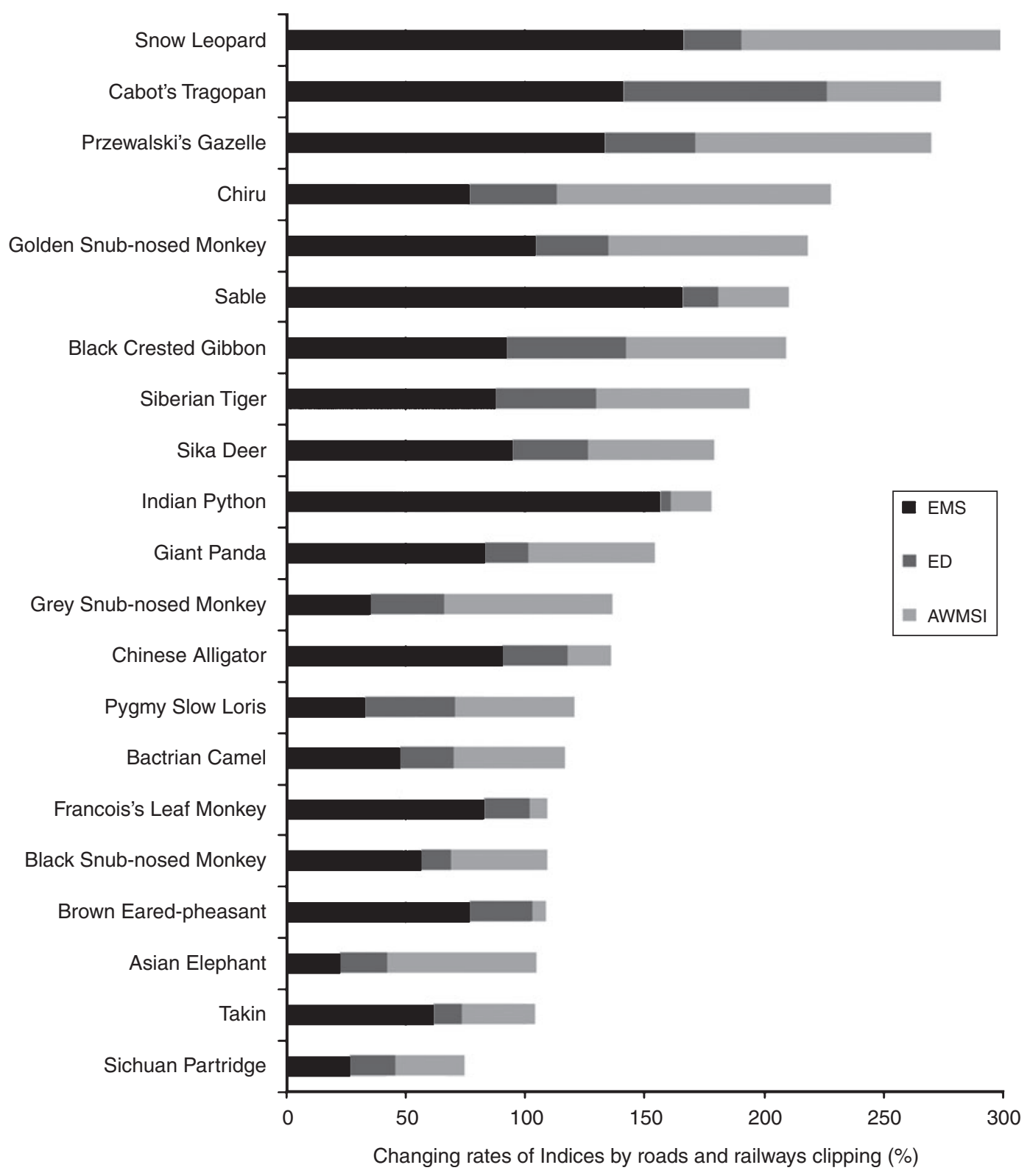

Fig. 4. Ranks of indices based in the rate of change (\%) for indicator species (between the road-clearing scenario and the road-intersection scenario). AWMSI, area-weighted mean shape index; ED, edge density; and EMS, effective mesh size.

present study differ in terms of their territory size, capacity for dispersal, perceived landscape pattern and responses to traffic impact. For example, the home range of Amur Siberian tigers (Panthera tigris altaica) in Sikhote-Alin Biosphere Zapovednik is $\sim 390 \mathrm{~km}^{2}$ ( $\pm 136 \mathrm{~km}^{2}$ ) for female individuals and $1385 \mathrm{~km}^{2}$ $\left( \pm 539 \mathrm{~km}^{2}\right)$ for male individuals (Goodrich et al. 2010). By contrast, the black crested gibbon (Nomascus concolor jingdongensis) requires only $\sim 1.51 \mathrm{~km}^{2}$ for a group as their daily home range (Fan and Jiang 2008). This indicates that Amur Siberian tigers must occupy a broader area to maintain their survival. Thus, if a rigid barrier appears in their habitat, their home-range area is likely to decrease below the minimum patch threshold, thereby causing population depression or extinction. In general, species with lower reproductive rates, greater mobilities, and larger body sizes are affected most negatively by traffic at the population level (Rytwinski and Fahrig 2011); however, an individual of a species with a greater mobility has a greater possibility of avoiding being killed by traffic than does a ground-nesting bird or a reptile (Tanner and Perry 2007). In addition, the behavioural mode of habitat selection tends to differ among seasons or life histories for some other species (Rytwinski and Fahrig 2012). Vertical migratory species, such as the giant panda, often utilise a winter habitat at lower elevations, which have higher road densities. Thus, the giant panda is more susceptible to traffic impacts during this period.

In the present study, we did not examine the behavioural patterns or differences in temporal dynamics among species for two reasons. First, we calculated the changes in the rates of 


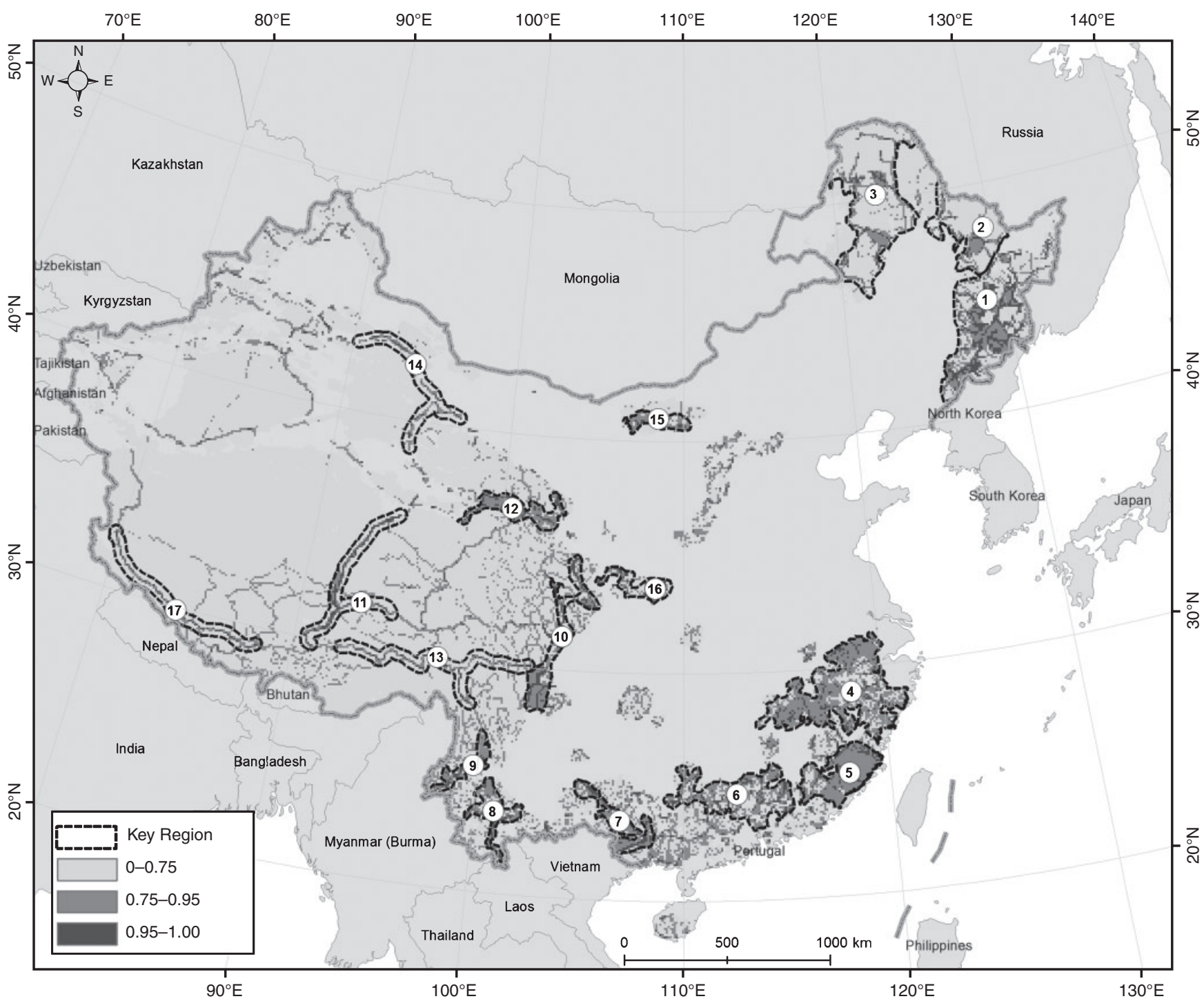

Fig. 5. Distribution of $\delta_{\mathrm{i}}$ values and key areas.1, Ji' an-Mishan; 2, Huanan-Beian; 3, Oroqen-Arxan; 4, Yixing-Wanzai-Fuan; 5, Changle-Yongan-Yunxia; 6, Dongyuan-Liujiang; 7, Pingxiang-Xingyi; 8, Mengla-Nanjian; 9, Ruili-Yulong; 10, Xide-Zhangxian; 11, Golmud-Lhasa; 12, Minhe-Dulan; 13, Gongbo'gvamda-Kangding; 14, Guazhou-Urumqi; 15, Tumote Right Banner-Dengkou; 16, Fengxian-Zhashui; 17, Gaer-Gongga.

metrics for each umbrella species to determine the contribution of traffic, as shown in Fig. 4. Thus, the variable compared among species was the degree of habitat fragmentation with or without traffic network for each species, rather than relative to other species, which partly eliminated the discrepancy produced by distinguishing their intrinsic behavioural modes. Second, the behavioural analysis was based on monitoring datasets that comprised high-quality species-presence records, which are difficult to obtain and not suitable for large-scale evaluations. This limitation in terms of data also affected the habitat estimation process. As mentioned in the Materials and methods section, our species presence data were recorded at a coarse resolution (e.g. county, mountain or natural reserve), and thus these data did not reflect the frequency of using different habitats by the indicator species. For example, there was a single point for the black snubnosed monkey in Mangkang county, which simply means that this species was observed once in this county. If many points had been included in one county, this would mean that the species was distributed in various regions (e.g. mountains and nature reserves) within the administrative boundary. It would be very difficult to collect a set of systematic field-sample data that cover the whole of mainland China. If we employ large-spread SDMs, such as Maxent (Phillips et al. 2006), Domain (Carpenter et al. 1993) or Biomapper (Hirzel et al. 2006), using limited sample data, then the outputs would probably be degraded by the imperfect detection of indicator species, and, thus, some patches would appear to be unoccupied when they are actually occupied (Hijmans and Graham 2006). Another problem encountered during habitat estimation is that we did not use key ecological variables such as temperature and precipitation data in habitat modelling, which is because we knew the distribution regions of indicator species at a county scale. At this scale, temperature and 
Table 2. Identification of road and railway sections in key areas

\begin{tabular}{|c|c|c|c|c|}
\hline Key area & Highway sections & National road sections & Railway sections & Indicator species \\
\hline Ji'an-Mishan & $\mathrm{G} 10, \mathrm{G} 11, \mathrm{G} 12$ & G201,G301,G302,G303 & $\begin{array}{l}\text { Line Fuqian, Line Jiafu, } \\
\text { Line Mujia, Line } \\
\text { Lindong, Line Binsui, } \\
\text { Line Mutu, Line } \\
\text { Changtu, Line Helong, } \\
\text { Line Yanbai, Line } \\
\text { Hunbai, Line Meiji, } \\
\text { Line Yada }\end{array}$ & $\begin{array}{l}\text { Siberian tiger, sika deer, } \\
\text { sable }\end{array}$ \\
\hline Huanan-Beian & G1011,G1111,G11 & $\mathrm{G} 201, \mathrm{G} 221, \mathrm{G} 222$ & $\begin{array}{l}\text { Line Beihei, Line Nanwu, } \\
\text { Line Suijia }\end{array}$ & Sable \\
\hline Oroqen-Arxan & G10 & G111,G301 & $\begin{array}{l}\text { Line Fuxi, Line Linbi, Line } \\
\text { Chaowu, Line Yijia, } \\
\text { Line Baia, Line Bolin, } \\
\text { Line Binman }\end{array}$ & Sable \\
\hline Yixing-Wanzai-Fuan & $\begin{array}{l}\mathrm{G} 3, \mathrm{G} 25, \mathrm{G} 35, \mathrm{G} 45, \\
\text { G50,G56,G60,G70 }\end{array}$ & $\begin{array}{l}\text { G105,G205,G206,G316, } \\
\text { G320,G330 }\end{array}$ & $\begin{array}{l}\text { Line Xuanhang, Line } \\
\text { Wangan, Line Jinwen, } \\
\text { Line Zhegan, Line } \\
\text { Hengnan, Line Yingxia, } \\
\text { Line Lede, Line Jingjiu, } \\
\text { Line Xiangle, Line } \\
\text { Zhangtang, Line Bajian, } \\
\text { Line Shangxin }\end{array}$ & $\begin{array}{l}\text { Cabot's tragopan, sika } \\
\text { deer, Chinese alligator }\end{array}$ \\
\hline Changle-Yongan-Yunxia & $\begin{array}{l}\mathrm{G} 15, \mathrm{G} 25, \mathrm{G} 72, \mathrm{G} 70, \\
\quad \mathrm{G} 76\end{array}$ & $\begin{array}{l}\text { G205,G206,G316,G319, } \\
\text { G324 }\end{array}$ & $\begin{array}{l}\text { Line Waifu, Line } \\
\text { Zhangquan, Line } \\
\text { Yingxia, Line } \\
\text { Zhanglong }\end{array}$ & Indian python \\
\hline Dongyuan-Liujiang & $\begin{array}{l}\text { G4,G35,G4511,G55, } \\
\quad \text { G72,G78 }\end{array}$ & $\begin{array}{l}\text { G105,G106,G107,G205, } \\
\text { G207,G209,G321,G322, } \\
\text { G323 }\end{array}$ & $\begin{array}{l}\text { Line Xianggui, Line } \\
\text { Tunqiu, Line Jingjiu, } \\
\text { Line Jingguang }\end{array}$ & $\begin{array}{l}\text { Indian python, Cabot's } \\
\text { tragopan }\end{array}$ \\
\hline Pingxiang-Xingyi & $\begin{array}{l}\text { G7211,G7511,G78, } \\
\text { G80 }\end{array}$ & G322,G323,G324,G325 & $\begin{array}{l}\text { Line Xianggui, Line } \\
\text { Nankun, Line Nanfang }\end{array}$ & $\begin{array}{l}\text { Francois's leaf monkey, } \\
\text { Indian python, sika deer }\end{array}$ \\
\hline Mengla-Nanjian & G8511 & $\mathrm{G} 213, \mathrm{G} 214, \mathrm{G} 215, \mathrm{G} 219$ & & $\begin{array}{l}\text { Black crested gibbon, } \\
\text { Indian python, Asian } \\
\text { elephant }\end{array}$ \\
\hline Ruili-Yulong & G56 & G214,G320 & & $\begin{array}{l}\text { Snow leopard, takin, black } \\
\text { snub-nosed monkey }\end{array}$ \\
\hline Xide-Zhangxian & G5 & $\begin{array}{l}\mathrm{G} 108, \mathrm{G} 212, \mathrm{G} 213, \mathrm{G} 316, \\
\text { G317,G318 }\end{array}$ & Line Chengkun & $\begin{array}{l}\text { Giant panda, golden snub- } \\
\text { nosed monkey, sika } \\
\text { deer, takin, Sichuan } \\
\text { partridge, snow leopard }\end{array}$ \\
\hline Golmud-Lhasa & & $\mathrm{G} 109, \mathrm{G} 317, \mathrm{G} 318$ & Line Jingzang & Chiru, snow leopard \\
\hline Minhe-Dulan & G6 & $\begin{array}{l}\text { G109,G214,G227,G312, } \\
\quad \text { G315 }\end{array}$ & $\begin{array}{l}\text { Line Jingzang, Line } \\
\text { Lanxin }\end{array}$ & $\begin{array}{l}\text { Przewalski's gazelle, snow } \\
\text { leopard }\end{array}$ \\
\hline Gongbo'gvamda-Kangding & & G214,G318 & & Takin, snow leopard \\
\hline Guazhou-Urumqi & G7,G30,G3013 & $\mathrm{G} 215, \mathrm{G} 216, \mathrm{G} 312, \mathrm{G} 314$ & Line Lanxin & $\begin{array}{l}\text { Bactrian camel, snow } \\
\text { leopard }\end{array}$ \\
\hline $\begin{array}{l}\text { Tumote Right } \\
\text { Banner-Dengkou }\end{array}$ & G6,G65 & $\mathrm{G} 110, \mathrm{G} 210$ & $\begin{array}{l}\text { Line Baobai, Line Baoshi, } \\
\text { Line Baolan }\end{array}$ & Snow leopard \\
\hline Fengxian-Zhashui & G5,G65 & G108,G210,G310,G316 & $\begin{array}{l}\text { Line Xikang, Line } \\
\text { Baocheng }\end{array}$ & $\begin{array}{l}\text { Giant panda, golden snub- } \\
\text { nosed monkey, takin }\end{array}$ \\
\hline Gaer-Gongga & & G219,G318 & & chiru, snow leopard \\
\hline
\end{tabular}

precipitation variables exhibit little spatial heterogeneity within a data unit (county). By contrast, ecosystem types and topographic variables are more dominant factors that influence species distributions. Thus, our method could not generate a continuous suitability map for each species, but it integrated a conceptual model and expert knowledge to produce informative Boolean habitat maps.
Implications for fragmentation measurement in habitats The study of fragmentation is so complex that it is difficult to quantify and compare. To assess the structure and heterogeneity of landscapes, landscape indices have been used widely to measure fragmentation (Girvetz et al. 2008; Giulio et al. 2009; Montefalcone et al. 2010; Baral et al. 2014), but these geometric landscape indices are usually constructed mathematically 
and they often fail to consider relationships with ecological processes.

However, for practical reasons, we selected three geometric indices to distinguish the degree of habitat separation, which are all known to be highly suitable as indicators for monitoring the sustainability of ecosystems and where the results obtained can be used to compare the degree of habitat fragmentation (Jaeger et al. 2008). In particular, the EMS reflects the degree of habitat division, but it also includes information about the status of core or large habitat patches. The AWMSI measures patch complexity, which is important for various ecological processes, especially habitat use by wildlife, e.g. circular areas tend to have a larger potential core area than do strip habitats. The ED is used to quantify the degree of impact owing to barriers generated by transport construction. In summary, these indices cannot provide a comprehensive description of habitat fragmentation, but much valuable information about habitat quality could be obtained from our calculations.

In fact, several other methods are available for measuring habitat fragmentation or connectivity (Nikolakaki 2004; Buij et al. 2007; Hortal and Saura 2007; Cushman et al. 2012; Freitas et al. 2012), including the probability of connectivity index or cost-distance analysis. In addition, the development of a transport network often marks a historical starting point in human penetration into the wilderness (Elvin 2004). Thus, the expansion of roads usually leads to environmental degradation, often with irreversible impacts on a finite ecosystem (Laurance et al. 2014). Furthermore, these detrimental effects tend to be intensified by subsequent anthropogenic stressors, including cropland, recreation, mining and residents. In some areas, these factors even dominate wildlife movements and dispersal more than do roads or railways (Wenger et al. 1999). Thus, it is necessary and appropriate to combine all of the impact factors that are correlated with traffic networks as a surrogate for road-impact assessment. The fragmentation effect caused by transport networks is highly complex and difficult to extract in its entirety. However, on the basis of evaluations of road and railway densities and their fragmentation effects on each indicator species, our results suggested that the habitats of species with narrow distributions, such as Chinese alligator and Sichuan partridge, had a relatively high traffic density, but the core habitat degradation was even more obvious for species with higher intrinsic mobility or greater area requirements (e.g. snow leopard, Przewalski's gazelle and chiru).

\section{Implications for conservation strategies}

Key areas with intense transport disturbance should be identified to facilitate conservation initiatives and to direct limited conservation resources towards the most crucial targets. This type of research often tends to be ignored because, for a single species, the key habitat that needs to be conserved may be located in a region with the highest road density. However, we considered many indicator species in this study, which forced us to select areas with severe road (railway) impacts, as well as areas with high species richness. This is very similar to the challenge of conservation site selection and we employed one of these algorithms in our study. The typical goal of these algorithms is to achieve the minimum representation of biodiversity features for the smallest possible cost (McDonnell et al. 2002). By focusing specifically on the impact of transportation, we identified 17 key areas with severe traffic impacts, which included 40 highway sections, 62 national road sections and 51 railway sections. This result can be depicted as a unit set with the maximum representation of road disturbance for the highest indicator species richness.

Our results suggested that several conservation strategies can be implemented to maximise wildlife preservation in the long term under intense transportation impacts. First, laws and management strategies should be strengthened. Given the very limited clauses in China's wildlife protection law, future legislative procedures should focus on protecting the integrity of habitats for rare wildlife. In the old version of the law, the focus mainly involved definitions and punitive measures for hunting and wildlife transactions, so habitat protection was neglected. Ideally, some additional legal terms should be compiled to ensure ecological representativeness and habitat connectivity, especially for the key regions that contain the important road or railway sections identified in our analysis. Central government, which is the starting point of the top-down management system in China, should clarify the responsibility of local government by law. More detailed conservation clauses should be formulated by local governments to cooperate with traffic and wildlife-research departments on the basis of knowledge of local characteristics. In addition, the list of rare species in law was decided in 1988 , which means that it is outdated. We suggest that the red list should reference some other notable lists that are used throughout the world, such as the IUCN Red List (IUCN 2013) and the appendix of CITES (CITES 1973). Second, ecological engineering should be performed to maintain habitat connectivity, where an effective measure may be the designation of habitat corridors to connect isolated habitat patches with the core habitats of target species, such as building eco-passages and landscape restoration efforts (Lesbarrères and Fahrig 2012). In addition, well planned conservation fences are an effective method for excluding rare species from over-fragmented habitat patches, thereby restricting the spread of infectious diseases, excluding humans from reserves and guiding species to use eco-passages (Bode and Wintle 2010). All of these methods can decrease the negative impacts of habitat fragmentation. Third, new transportation planning should consider our results by keeping new roads away from key regions, or at least away from the core patches with a high probability of occupancy by rare species. During road or railway construction, noise, waste disposal and the selection criterion of engineering materials should be supervised by the appropriate environmental protection agency to minimise disturbances. Sites of wildlife presence need to be recorded along roadsides, which can provide valuable information for future conservation efforts. In contrast to roadside conservation, railway departments should take some specialised measures to promote wildlife protection. Locomotive upgrading is a desirable approach, e.g. vacuum-toilet wastewater collectors, trash compactors and advanced sewage treatment systems have been used on the Qinghai-Tibet railway to avoid environmental pollution (Jiang et al. 2006). However, these new techniques are rarely employed because of their high manufacturing and application costs. Therefore, future train upgrades can focus on the key sections identified in the present study as a priority. 
As proxies for measuring and predicting the impacts of traffic on rare habitats, the driving forces of transport-network development should be better understood because they are linked directly to issues of wildlife conservation. In general, well developed areas with high road accessibility will have more severe traffic impacts. Similarly, calculating Pearson's correlation coefficient (using key areas as analytical units) shows that the road and railway density is positively correlated with the population density $(r=0.487, P=0.048)$ and GDP density $(r=0.647, P=0.005)$, but negatively correlated with average elevation $(r=0.511, P=0.036)$. This indicates that different conservation strategies are needed in developed areas (e.g. areas 4, 5, 6, and 15 in Fig. 5) compared with undeveloped areas. In the developed eastern area with a greater human footprint, an effective method for protecting habitat integrity might be the establishment of a comprehensive conservation plan for core protected areas linked by semi-protected corridors across the intensive traffic network because total habitat loss is more likely than a simple decline in habitat quality in these over-fragmented areas (Barber et al. 2014). By contrast, in remote regions, a less stringent policy such as road closure during the critical period for species migration may be a more suitable and feasible approach for reducing traffic disturbances (Qiu and Feng 2004; Switalski and Nelson 2011). Furthermore, habitat degradation is economically driven and transport construction will increase economic growth. Thus, future research should focus on the traffic or economic capacity of the identified areas. If road construction reaches this capacity, this means that the marginal costs of habitat degradation will overwhelm the marginal benefits of traffic construction. At present, relevant government departments should consider ending construction and focusing on habitat conservation.

\section{Acknowledgements}

This project was funded by the public welfare project in Ministry of Land and resources (201011018). We thank Professor Falk Huettmann, and anonymous reviewers for providing constructive suggestions of the manuscript. We thank Transport Planning and Research Institute, Ministry of Transport of the People's Republic of China for providing transportation planning data.

\section{References}

Baral, H., Keenan, R. J., Sharma, S. K., Stork, N. E., and Kasel, S. (2014). Spatial assessment and mapping of biodiversity and conservation priorities in a heavily modified and fragmented production landscape in north-central Victoria, Australia. Ecological Indicators 36, 552-562. doi:10.1016/j.ecolind.2013.09.022

Barber, C. P., Cochrane, M. A., Souza, C. M., and Laurance, W. F. (2014). Roads, deforestation, and the mitigating effect of protected areas in the Amazon. Biological Conservation 177, 203-209. doi:10.1016/j.biocon. 2014.07.004

Blair, C., Weigel, D. E., Balazik, M., Keeley, A. T. H., Walker, F. M., Landguth, E., Cushman, S., Murphy, M., Waits, L., and Balkenho, N. (2012). A simulation-based evaluation of methods for inferring linear barriers to gene flow. Molecular Ecology Resources 12, 822-833. doi:10.1111/j.1755-0998.2012.03151.x

Bode, M., and Wintle, B. (2010). How to build an efficient conservation fence. Conservation Biology 24, 182-188. doi:10.1111/j.1523-1739.2009. 01291.x
Buij, R., McShea, W. J., Campbell, P., Lee, M. E., Dallmeier, F., Guimondou, S., Mackaga, L., Guisseougou, N., Mboumba, S., Hines, J. E., Nichols, J. D., and Alonso, A. (2007). Patch-occupancy models indicate human activity as major determinant of forest elephant (Loxodontacyclotis) seasonal distribution in an industrial corridor in Gabon. Biological Conservation 135, 189-201. doi:10.1016/j.biocon.2006.10.028

Byrnes, P., Goosem, M., and Turton, S. M. (2012). Are less vocal rainforest mammals susceptible to impacts from traffic noise? Wildlife Research $\mathbf{3 9}$, 355-365. doi:10.1071/WR11010

Carpenter, G., Gillison, A. N., and Winter, J. (1993). Domain: a flexible modelling procedure formapping potential distributions of plants and animals. Biodiversity and Conservation 2, 667-680. doi:10.1007/ BF00051966

Chinese Academy of Sciences(CAS) (2005). 'Chinese Biodiversity Information System.' Available at cbis.brim.ac.cn/ [verified 20 May 2010]

Appendices of Convention on International Trade in Endangered Species of Wild Fauna and Flora (1973). The Executive Office of Endangered Species Scientific Commission, P.R.C., Available at http://www.cites. org.cn/ [verified 1 September 2013]

Coffin, A. W. (2007). From road kill to road ecology: a review of the ecological effects of roads. Journal of Transport Geography 15, 396-406. doi:10.1016/j.jtrangeo.2006.11.006

Cushman, S. A., Landguth, E. L., and Flather, C. H. (2012). Evaluating the sufficiency of protected lands for maintaining wildlife population connectivity in the US northern Rocky Mountains. Diversity \& Distributions 18, 873-884. doi:10.1111/j.1472-4642.2012.00895.x

Elvin, M. (2004). 'The Retreat of the Elephants: an Environmental History of China.' (Yale University Press: New Haven, CT.)

Fan, P. F., and Jiang, X. L. (2008). Effects of food and topography on ranging behavior of black crested gibbon (Nomascus concolor jingdongensis) in Wuliang Mountain, Yunnan, China. American Journal of Primatology 70, 871-878. doi:10.1002/ajp.20577

Fan, J. T., Li, J. S., Quan, Z. J., Wu, X. P., Hu, L. L., and Yang, Q. P. (2011). Impact of road construction on giant panda's habitat and its carrying capacity in Qinling Mountains. Acta Ecologica Sinica 31, 145-149. doi:10.1016/j.chnaes.2011.03.003

Forman, R. T. T., and Alexander, L. E. (1998). Roads and their major ecological effects. Annual Review of Ecology and Systematics 29, 207-231. doi:10.1146/annurev.ecolsys.29.1.207

Forman, R. T. T., Sperling, D., Bissonette, J. A., Clevenger, A. P., Cutshall, C. D., Dale, V. H., Fahrig, L., France, R., Goldman, C. R., Heanue, K., Jones, J. A., Swanson, F. J., Turrentine, T., and Winter, T. C. (2003). 'Road Ecology. Science and Solutions.' (Island Press: Washington, DC.)

Freitas, S. R., Alexandrino, M. M., Pardini, R., and Metzger, J. P. (2012). A model of road effect using line integrals and a test of the performance of two new road indices using the distribution of small mammals in an Atlantic Forest landscape. Ecological Modelling 247, 64-70. doi:10.1016/ j.ecolmodel.2012.07.033

Girvetz, E. H., Thorne, J. H., Berry, A. M., and Jaeger, J. A. G. (2008). Integration of landscape fragmentation analysis into regional planning: a statewide multi-scale case study from California, USA. Landscape and Urban Planning 86, 205-218. doi:10.1016/j.landurbplan.2008.02.007

Giulio, M., Holderegger, R., and Tobias, S. (2009). Effects of habitat and landscape fragmentation on humans and biodiversity in densely populated landscapes. Journal of Environmental Management 90, 2959-2968. doi:10.1016/j.jenvman.2009.05.002

Goodrich, J. M., Miquelle, D. G., Smirnov, E. N., Kerley, L. L., Quigley, H. B., and Hornocker, M. G. (2010). Spatial structure of Amur (Siberian) Siberian tigers (Pantheratigrisaltaica) on Sikhote-Alin biosphere Zapovednik, Russia. Journal of Mammalogy 91, 737-748. doi:10.1644/ 09-MAMM-A-293.1

Grilo, C., Bissonette, J. A., and Reis, M. S. (2009). Spatial-temporal patterns in Mediterranean carnivore road casualties: consequences for mitigation. 
Biological Conservation 142, 301-313. doi:10.1016/j.biocon.2008.10. 026

Harris, R. B. (2008). 'Wildlife Conservation in China: Preserving the Habitat of China's Wild West.' (M.E. Sharpe: New York.)

Hijmans, R. J., and Graham, C. H. (2006). Testing the ability of climate envelope models to predict the effect of climate change on species distributions. Global Change Biology 12, 2272-2281. doi:10.1111/ j.1365-2486.2006.01256.x

Hinam, H. L., and St. Clair, C. C. (2008). High levels of habitat loss and fragmentation limit reproductive success by reducing home range size and provisioning rates of northern saw-whet owls. Biological Conservation 141, 524-535. doi:10.1016/j.biocon.2007.11.011

Hirzel, A. H., Hausser, J., and Perrin, N. (2006). 'Biomapper 3.2.' (Laboratory of Conservation Biology, Department of Ecology and Evolution, University of Lausanne: Lausanne, Switzerland.) Available at www2. unil.ch/biomapper/ [verified 16 June 2009]

Hortal, L. P., and Saura, S. (2007). A new habitat availability index to integrate connectivity in landscape conservation planning: comparison with existing indices and application to a case study. Landscape and Urban Planning 83, 91-103. doi:10.1016/j.landurbplan.2007.03.005

Huettmann, F. (2012). From Europe to North America into the world and atmosphere: a short review of global footprints and their impacts and predictions. The Environmentalist 32, 289-295. doi:10.1007/s10669011-9338-5

IUCN, 2013 IUCN, 2013. The IUCN Red List of threatened species. URL: http://www.redlist.org/ [verified 01 January 2014].

Jackson, N. D., and Fahrig, L. (2011). Relative effects of road mortality and decreased connectivity on population genetic diversity. Biological Conservation 144, 3143-3148. doi:10.1016/j.biocon.2011.09.010

Jaeger, J. A. G. (2000). Landscape division, splitting index, and effective mesh size: new measures of landscape fragmentation. Landscape Ecology 15, 115-130. doi:10.1023/A:1008129329289

Jaeger, J. A. G., Bertiller, R., Schwick, C., Müller, K., Steinmeier, C., Ewald, K. C., and Ghazoul, J. (2008). Implementing landscape fragmentation as an indicator in the Swiss monitoring system of sustainable development (MONET). Journal of Environmental Management 88, 737-751. doi:10.1016/j.jenvman.2007.03.043

Jenkins, C. N., and Joppa, L. (2009). Expansion of the global terrestrial protected area system. Biological Conservation 142, 2166-2174. doi:10.1016/j.biocon.2009.04.016

Jiang, C., La, B., and Chen, L. (2006). Qinghai-Tibet railway: an environmental friendly railway. Available at http://www.cgs.gov.cn/ cgjz/sgh/rdzt/qztljx/mtjj/14265.htm [verified 13 June 2007]

Kindlmann, P., and Burel, F. (2008). Connectivity measures: a review. Landscape Ecology 23, 879-890. doi:10.1007/s10980-008-9245-4

Laurance, W. F., Goosem, M., and Laurance, S. G. W. (2009). Impacts of roads and linear clearings on tropical forests. Trends in Ecology \& Evolution 24, 659-669. doi:10.1016/j.tree.2009.06.009

Laurance, W. F., Clements, G. R., Sloan, S., O’Connell, C. S., Mueller, N. D., Goosem, M., Venter, O., Edwards, D. P., Phalan, B., Balmford, A., Van Der Ree, R., and Arrea, I. B. (2014). A global strategy for road building. Nature 513, 229-232. doi:10.1038/nature 13717

Lesbarrères, D., and Fahrig, L. (2012). Measures to reduce population fragmentation by roads: what has worked and how do we know? Trends in Ecology \& Evolution 27, 374-380. doi:10.1016/j.tree.2012. 01.015

Li, H., and Wu, J. (2004). Use and misuse of landscape indices. Landscape Ecology 19, 389-399. doi:10.1023/B:LAND.0000030441.15628.d6

Li, C. W., Jiang, Z. G., Feng, Z. J., Yang, X. B., Yang, J., and Chen, L. W. (2009). Effects of highway traffic on diurnal activity of the critically endangered Przewalski's gazelle. Wildlife Research 36, 379-385. doi:10.1071/WR08117

Li, Z. Q., Ge, C., Li, J., Li, Y. K., Xu, A. J., Zhou, K. X., and Xue, D. Y. (2010). Ground-dwelling birds near the Qinghai-Tibet highway and railway.
Transportation Research Part D. Transport and Environment 15, 525-528. doi:10.1016/j.trd.2010.07.004

Linke, J., Franklin, S. E., Huettmann, F., and Stenhouse, G. B. (2005). Seismic cutlines, changing landscape metrics and grizzly bear landscape use in Alberta. Landscape Ecology 20, 811-826. doi:10.1007/s10980-0050066-4

Liu, J. G., Linderman, M., Ouyang, Z. Y., An, L., Yang, J., and Zhang, Z. M. (2001). Ecological degradation in protected areas: the case of Wolong Nature Reserve forgiant pandas. Science 292, 98-101. doi:10.1126/ science. 1058104

Liu, S. L., Cui, B. S., Dong, S. K., Yang, Z. F., Yang, M., and Holt, K. (2008). Evaluating the influence of road networks on landscape and regional ecological risk: a case study in Lancang River Valley of southwest China. Ecological Engineering 34, 91-99. doi:10.1016/j.ecoleng.2008.07.006

López, A. B., Alkemade, R., and Verweij, P. A. (2010). The impacts of roads and other infrastructure on mammal and bird populations: a meta-analysis. Biological Conservation 143, 1307-1316. doi:10.1016/j.biocon.2010. 02.009

Lu, N., Jia, C. X., Lloyd, H., and Sun, Y. H. (2012). Species-specific habitat fragmentation assessment, considering the ecological niche requirements and dispersal capability. Biological Conservation 152, 102-109. doi:10.1016/j.biocon.2012.04.004

McDonnell, M. D., Possingham, H. P., Ball, I. R., and Cousins, E. A. (2002). Mathematical methods for spatially cohesive reserve design. Environmental Modeling and Assessment 7, 107-114. doi:10.1023/ A:1015649716111

McGarigal, K., Cushman, S. A., and Ene, E. (2012). 'FRAGSTATS v4: Spatial Pattern Analysis Program for Categorical and Continuous Maps.' Computer software program produced by the authors at the University of Massachusetts, Amherst. Available at http://www.umass.edu/landeco/ research/fragstats/fragstats.html [verified 1January 2013]

Moilanen, A. (2007). Landscape zonation, benefit functions and target-based planning: unifying reserve selection strategies. Biological Conservation 134, 571-579. doi:10.1016/j.biocon.2006.09.008

Montefalcone, M., Parravicini, V., Vacchi, M., Albertelli, G., Ferrari, M., Morri, C., and Bianchi, C. N. (2010). Human influence on seagrass habitat fragmentation in NW Mediterranean Sea. Estuarine, Coastal and Shelf Science 86, 292-298. doi:10.1016/j.ecss.2009.11.018

Morgan, G. M., Wilcoxen, T. E., Rensel, M. A., and Schoech, S. J. (2012). Are roads and traffic sources of physiological stress for the Florida scrub-jay? Wildlife Research 39, 301-310. doi:10.1071/WR11029

Moser, B., Jaeger, J. A. G., Tappeiner, U., Tasser, E., and Eiselt, B. (2007). Modification of the effective mesh size for measuring landscape fragmentation to solve the boundary problem. Landscape Ecology 22, 447-459. doi:10.1007/s10980-006-9023-0

National Bureau of Statistics of the People's Republic of China (2003). Annual Report of traffic network development of China, 2000. Available at www.stats.gov.cn/tjgb/qttjgb/qgqttjgb/t20020331_15498. htm [verified 31 March 2002].

National Bureau of Statistics of the People's Republic of China (2006). Annual Report of traffic network development of China, 2005. Available at www.stats.gov.cn/tjfx/ztfx/swcj/t20060320_402311602.htm [verified 20 March 2006].

National Bureau of Statistics of the People's Republic of China (2011). Annual Report of traffic network development of China, 2010. Available at www.stats.gov.cn/tjfx/ztfx/sywcj/t20110303_402707375.htm [verified 03 March 2011].

Nielsen, S. E., McDermid, G., Stenhouse, G. B., and Boyce, M. S. (2010). Dynamic wildlife habitat models: seasonal foods and mortality risk predict occupancy-abundance and habitat selection in grizzly bears. Biological Conservation 143, 1623-1634. doi:10.1016/j.biocon.2010.04.007

Nikolakaki, P. (2004). A GIS site-selection process for habitat creation: estimating connectivity of habitat patches. Landscape and Urban Planning 68, 77-94. doi:10.1016/S0169-2046(03)00167-1 
Olson, D. M., Dinerstein, E., Wikramanayake, E. D., Powell, G. V. N., Underwood, E. C., and D'amico, J. A. (2001). Terrestrial ecoregions of the world: a new map of life on Earth. Bioscience 51, 933-938. doi:10.1641/ 0006-3568(2001)051[0933:TEOTWA]2.0.CO;2

Phillips, S. J., Anderson, R. P., and Schapire, R. E. (2006). Maxemum entropy modeling of species geographic distributions. Ecological Modelling 190, 231-259. doi:10.1016/j.ecolmodel.2005.03.026

Primack, R. B. (2012). 'A Primer of Conservation Biology.' 5th edn. (Sinauer Associates: Sunderland, MA.)

Qiu, L., and Feng, Z. (2004). Effects of traffic during daytime and other human activities on the migration of Tibetan antelope along the Qinghai-Tibet high-way, Qinghai-Tibet Plateau. Acta Zoologica Sinica 50, 669-674. [Chinese with English abstract]

Reiter, G., Pölzer, E., Mixanig, H., Bontadina, F., and Hüttmeir, U. (2013). Impact of landscape fragmentation on a specialised wood land bat, Rhinolophus hipposideros. Mammalian Biology 78, 283-289. doi:10.1016/j.mambio.2012.11.003

Rondinini, C., and Doncaster, C. P. (2002). Roads as barriers to movement for hedgehogs. Functional Ecology 16, 504-509. doi:10.1046/j.13652435.2002.00651.x

Rytwinski, T., and Fahrig, L. (2011). Reproductive rates and body size predict road impacts on mammal abundance. Ecological Applications 21, 589-600. doi:10.1890/10-0968.1

Rytwinski, T., and Fahrig, L. (2012). Do species life history traits explain population responses to roads? A meta-analysis. Biological Conservation 147, 87-98. doi:10.1016/j.biocon.2011.11.023

Scholes, R. J., and Biggs, R. (2004). 'Ecosystem Services In Southern Africa: a Regional Assessment.' Available at http://www.unep.org/maweb/ documents_sga/ [verified 20 December 2005]

State Forestry Administration of China (2010). 'Lists of Wildlife under Special State Protection.' (State Forestry Administration of China: Beijing.)

Switalski, T. A., and Nelson, C. R. (2011). Efficacy of road removal for restoring wildlife habitat: black bear in the northern Rocky Mountains, USA. Biological Conservation 144, 2666-2673. doi:10.1016/j.biocon. 2011.07.026

Tanner, D., and Perry, J. (2007). Road effects on abundance and fitness of Galápagos lava lizards (Microlophus albemarlensis). Journal of
Environmental Management 85, 270-278. doi:10.1016/j.jenvman.2006. 08.022

Taylor, B. D., and Goldingay, R. L. (2010). Roads and wildlife: impacts, mitigation and implications for wildlife management in Australia. Wildlife Research 37, 320-331. doi:10.1071/WR09171

Tiefenbacher., J. (2012). 'Perspectives on Nature Conservation: Patterns, Pressures and Prospects.' (Romana Vukelic: Rijeka.)

Uuemaa, E., Antrop, M., Roosaare, J., Marja, R., and Mander, U. (2009). 'Landscape Metrics and Indices: an Overview of Their Use in Landscape Research.' Living Reviews in Landscape Research 3. Available at http://www.livingreviews.org/lrlr-2009-1

Van Langevelde, F., Van Dooremalen, C., and Jaarsma, C. F. (2009). Traffic mortality and the role of minor roads. Journal of Environmental Management 90, 660-667. doi:10.1016/j.jenvman.2007.09.003

Wenger, R. B., Harris, H. J., Sivanpillai, R., and DeVault, D. S. (1999). A graph-theoretic analysis of relationships among ecosystem stressors. Journal of Environmental Management 57, 109-122. doi:10.1006/ jema.1999.0294

Wildlife Conservation Society China (WCSC) (2001). 'China Species Information System.' Available at csis.baohudi.org/csis_search/index. php [verified 14 June 2010].

Williams, P. H., Burgess, N. D., and Rahbek, C. (2000). Flagship species, ecological complementarity and conserving the diversity of mammals and birds in sub-Saharan Africa. Animal Conservation 3, 249-260. doi:10.1111/j.1469-1795.2000.tb00110.x

Wu, R., Zhang, S., Yu, D. W., Zhao, P., Li, X., Wang, L., Yu, Q., Ma, J., Chen, A., and Long, Y. (2011). Effectiveness of China's nature reserves in representing ecological diversity. Frontiers in Ecology and the Environment 9, 383-389. doi:10.1890/100093

Xu, W., Wang, X., Ouyang, Z., Zhang, J., Li, Z., Xiao, Y., and Zheng, H. (2009). Conservation of giant panda habitat in South Minshan, China, after the May 2008 earthquake. Frontiers in Ecology and the Environment 7, 353-358. doi:10.1890/080192

Zhang, M., Cheong, K., Leong, K., and Zou, F. (2012). Effect of traffic noise on black-faced spoonbills in the Taipa-Coloane Wetland Reserve, Macao. Wildlife Research 39, 603-610. doi:10.1071/WR12060 